Check for updates

London, UK

Cite this as: BMJ 2020;371:m4660 http://dx.doi.org/10.1136/bmj.m4660 Published: 26 November 2020

\section{Covid-19 has harmed poorest countries the most across Asia Pacific, says OECD}

\author{
Lynn Eaton
}

The covid-19 pandemic has highlighted existing gaps in healthcare within the Asia Pacific region and reinforced differences between rich and poor, a report from the Organisation for Economic Co-operation and Development (OECD) has concluded. ${ }^{1}$

The pandemic has had a disproportionate impact on the most vulnerable populations, said officials from the OECD and the World Health Organization in the foreword to the report.

The report outlines the challenges the pandemic has posed to improving health outcomes in low and middle income countries in the region in line with sustainable development goals.

The biennial study monitors 27 countries and territories in the region-ranging from Australia and New Zealand to China, India, Myanmar, and Vietnam. These are classified into four income groups-high, upper middle, lower middle, and low-based on their gross national income per capita. All have felt the impact of covid-19 in terms of population health and the economy.

Francesca Colombo, head of health at the OECD, told The BMJ that the pandemic had highlighted the need for more resilient health systems, especially in low to middle income countries. "A number of countries were moving in the right direction towards universal health coverage," she said. "Covid-19 is a great shock which will have major consequences for healthcare systems."

Colombo said it remained crucially important to invest in health in spite of the financial challenges of the pandemic. "If the health system is not strong enough, the consequences for society can be severe," she said. "While there is a growing number of older people and non-communicable diseases, we have to bear in mind that infectious diseases can still be a major shock that we have to be prepared to deal with. And prevention should not be cut in moments when there are budgetary difficulties.” increased in line with economic growth over the past seven years, there is still a disparity between countries. Health spending is $4 \%$ of gross domestic product in low and middle income countries, while it is $7 \%$ in high income countries.

On a more positive note, life expectancy at birth increased by six years across lower middle and low income Asia Pacific countries, reaching 70 years in 2018 , an increase of six years since 2000.

But the report noted that by 2050, the proportion of the population aged over 65 years is expected to almost double in high income countries, and rise by as much as two and a half times in low to middle income countries. This trend will have an impact on health finances, which many countries are unprepared for, it said.

Other trends observed included:

- Infant mortality has halved across lower middle and low income countries since 2000

- There was an average of 27.2 deaths per 1000 live births in 2018, more than double the Sustainable Development Goal target of 12 deaths per 1000 live births

- Basic sanitation and access to drinking water are still among the risk factors, alongside smoking tobacco, drinking alcohol, and being overweight.

The report also highlights disparities in healthcare staff across the region. There is one doctor per 1000 population in lower middle and low income countries, compared with 1.2 per 1000 in upper middle income countries. The number of doctor consultations also varied widely (see table).

And there is less than one nurse per 2000 population in Papua New Guinea, Pakistan, and Bangladesh, compared with around 12 nurses per 1000 population in Australia, Japan, and New Zealand.
Although overall health spending in the region has 


\section{| Doctor consultations per capita, latest year available}

\begin{tabular}{|c|c|}
\hline Korea, Rep (2018) & 16.9 \\
\hline Japan (2017) & 12.6 \\
\hline Hong Kong, China (2011) & 11.2 \\
\hline Macao, China (2018) & 8.6 \\
\hline Australia (2018) & 7.8 \\
\hline OECD average & 6.7 \\
\hline Sri Lanka (2016) & 6.0 \\
\hline China (2018) & 6.0 \\
\hline Mongolia (2017) & 5.7 \\
\hline Brunei Darussalam (2008) & 3.9 \\
\hline New Zealand (2017) & 3.8 \\
\hline Malaysia (2010) & 3.5 \\
\hline Fiji (2010) & 2.9 \\
\hline Viet Nam (2010) & 2.3 \\
\hline Thailand (2005) & 2.1 \\
\hline Singapore (2013) & 1.7 \\
\hline Papua New Guinea (2010) & 1.6 \\
\hline Solomon Islands (2006) & 1.5 \\
\hline Cambodia (2015) & 0.6 \\
\hline Bangladesh (2010) & 0.4 \\
\hline
\end{tabular}

1 OECD. Health at a glance: Asia Pacific 2020: measuring progress towards universal health coverage. November 2020. www.oecd.org/health/health-at-a-glance-asia-pacific-23054964.htm 